\title{
DEVELOPMENT OF TOOLS AND TECHNIQUES TO SURVEY, ASSESS, STABILISE, MONITOR AND PRESERVE UNDERWATER ARCHAEOLOGICAL SITES: SASMAP.
}

\author{
D. J. Gregory.
}

The National Museum of Denmark,The Conservation Department, I.C. Modewegs Vej, Brede, Kongens Lyngby, DK-2800,

Denmark - david.john.gregory@natmus.dk

KEY WORDS: Underwater cultural heritage, in situ preservation, location, assessment, management, monitoring

\begin{abstract}
:
SASMAP's purpose is to develop new technologies and best practices in order to locate, assess and manage Europe's underwater cultural heritage in a more effective way than is possible today. SASMAP has taken an holistic- and process- based approach to investigating underwater environments and the archaeological sites contained therein. End user of the results of SASMAP are severalfold; i) to benefiet the SMEs involved in the project and development of their products for the offshore industry (not just for archaeological purposes) ii) a better understanding of the marine environment and its effect on archaeological materials iii) the collation of the results from the project into guidelines that can be used by cultural resource managers to better administer and optimise developer lead underwater archaeological project within Europe in accordance with European legislation (Treaty of Valetta (1992).

Summarily the project has utilised a down scaling approach to localise archaeological sites at a large scale regional level. This has involved using innovative satellite imagery to obtain seamless topography maps over coastal areas and the seabed (accurate to a depth of $6 \mathrm{~m}$ ) as well as the development of a 3D sub bottom profiler to look within the seabed. Results obtained from the downscaling approach at the study areas in the project (Greece and Denmark) have enabled geological models to be developed inorder to work towards predictive modelling of where submerged prehistoric sites may be encountered. Once sites have been located an upscaling approach has been taken to assessing an individual site and the materials on and within it in order to better understand the state of preservation and dynamic conditions of a site and how it can best be preserved through in situ preservation or excavation. This has involved the development of equipment to monitor the seabed environment (open water and in sediments), equipment for sampling sediments and assessing the state of preservation of wood, once of the common materials on archaeological sites.

The guidelines and all information and experiences obtained during the course of the project will be utilised to enhance and develop existing legislation and best practice for mapping and preserving Europe's underwater and coastal heritage. The project started in September 2012 and finished at the end of August 2015 and the aim of the paper is to give a brief introduction to the results of the project. Further information on the project is available at www.sasmap.eu
\end{abstract}

\section{IN SITU PRESERVATION OF UNDERWATER CULTURAL HERITAGE}

In-situ preservation is increasingly being seen as a means to manage marine archaeological sites which, for economic reasons and current international trends favouring in-situ preservation, are not excavated, raised and conserved. This is both the case within Europe (Valetta Treaty, 1992) and UNESCO Convention for the Protection of underwater cultural heritage. Both these treaties advocate that, as a first option, the underwater cultural heritage should be protected in situ and, where possible, non-intrusive methods to document and study these sites in situ should be used. This is understandable in terms of the underwater cultural heritage resource. UNESCO currently estimates that, "over 3 million wrecks are spread across ocean floors around the planet" (http://www.unesco.org/en/the-underwater-culturalheritage/underwater-cultural-heritage/wrecks/).

However, in-situ preservation should not be a case of leaving a site where it is and hoping that it will be there when archaeologists and conservators have the capacity, research questions and desire to investigate these finds in the future. The current author (Gregory 2009) has previously discussed that there are five fundamental steps to ensuring the successful and responsible in-situ preservation and management of archaeological sites in general. These are:

1.the extent of the site to be preserved; 2.the most significant physical, chemical and biological threats to the site;

3.the types of materials present on the site and their state of preservation;

4.strategies to mitigate deterioration and stabilise the site from natural impacts; and

5.subsequent monitoring of a site and implemented mitigation strategies.

\section{WHAT IS SASMAP?}

SASMAP's purpose was to develop new technologies and best practices in order to address the above five points in order to be able to locate, assess and manage Europe's underwater cultural heritage in a more effective way. SASMAP took an holistic- and process- based approach to investigate underwater environments and the archaeological sites contained therein.

Cost effective methods to locate and assess the dimensions of archaeological sites both on and beneath the seabed are essential. The presence and extent of potential threats to archaeology must also be determined. Threats may arise from the natural physical environment including strong currents, from manmade hazards such as dredging, from construction work, fishing, installation of pipe/cable lines and development of recreation centres. The stability of the site and the state of preservation of the artefacts present must also be assessed. The various assessments provide information on how best to approach or manage a site. If the physical and bio-/geochemical 
environments are unstable or pose a threat to the site, the opportunities for stabilising it in situ must be determined. The options for monitoring the continued integrity of the site must be identified. If none exist, it needs to be determined whether areas can be identified that need to be excavated, or sampled non-destructively, before information is lost.

The results of SASMAP will benefit the management of underwater cultural heritage in Europe and in the rest of the world by providing end-users and stakeholders such as archaeologists, conservators and cultural resource managers with valuable tools and guidelines to better plan for the preservation of offshore archaeological sites and their contents in accordance with both the Treaty of Valletta (1992).

\section{RESEARCH \& INNOVATION: THE SASMAP CONCEPT}

The SASMAP concept involved developing and utilising tools and technologies to allow "down-scaling" from the large scale regional level, moving on to the local site level and finally to the individual components of a site. SASMAP had multiple scientific objectives that were all aimed at developing a structured and optimized approach to safeguarding underwater cultural heritage. Of necessity for such a project and certainly one of the great advantages of European funded projects, is the possibility to create an international and interdisciplinary research team. SASMAP brought together a consortium of seven governmental research institutions and four Small Medium Enterprises (SMEs) from seven European countries.

The partners comprised an interdisciplinary group with the SMEs having expertise in the development and production of state of the art marine geophysical instruments, equipment for measuring bio-geochemical parameters in the marine environment, protection of sub-sea installations (pipelines, cables) and hand held diving tools. Institutional partners encompass a synergistic group of researchers in marine archaeology and conservation, in situ preservation, wood degradation, marine geochemistry and marine geophysics working in museums, universities and other governmental institutions.

One of the key focuses of the call for applications to the European Union was to enhance the synergy between governmental research institutions and small businesses (SMES) in order to enhance the European economy. Thus, although one of the primary goals was to improve underwater cultural heritage management an equally important aim was to provide the small companies involved in the project the possibility of developing products from their own research pipeline.

With this in mind the scientific objectives of the project were divided up into the following scientific themes and are briefly described below with selected results:

\subsection{Downscaling}

Involves how to best locate and assess the potential of finding where underwater archaeological sites are on a regional level and then how to accurately survey and locate them for further investigation. Within SASMAP this was achieved through developing models and the development and application of novel remote sensing techniques.

3.1.1 Geological models for regional evaluation of probability of locating archaeological sites and their preservation potential.
Marine geological investigations are essential to develop a model describing the palaeogeographical and depositional environments in selected study areas in Denmark and Greece. The case study in Denmark was to reconstruct the palaeolandscape and to build a geological model of a submerged prehistoric landscape in order to develop a predictive model of where archaeological sites could potentially exist based upon sealevel change.. Existing information from this multidisciplinary field included seismic, sedimentological, biostratigraphic and AMS C-14 dating data. Based on these data the changing geological environments, as well as the palaeogeography, were reconstructed on two case sites in Denmark and Greece with respect to sedimentary conditions and water level fluctuations that occurred in the course of the various postglacial lake stages, as well as regional sea level changes.

On the basis of the geological model it was possible to optimise the process of selecting the target region ideal for nondestructive down-scaling studies using state of the art remote sensing techniques. An example from the Danish case study site is shown in Figure 1.

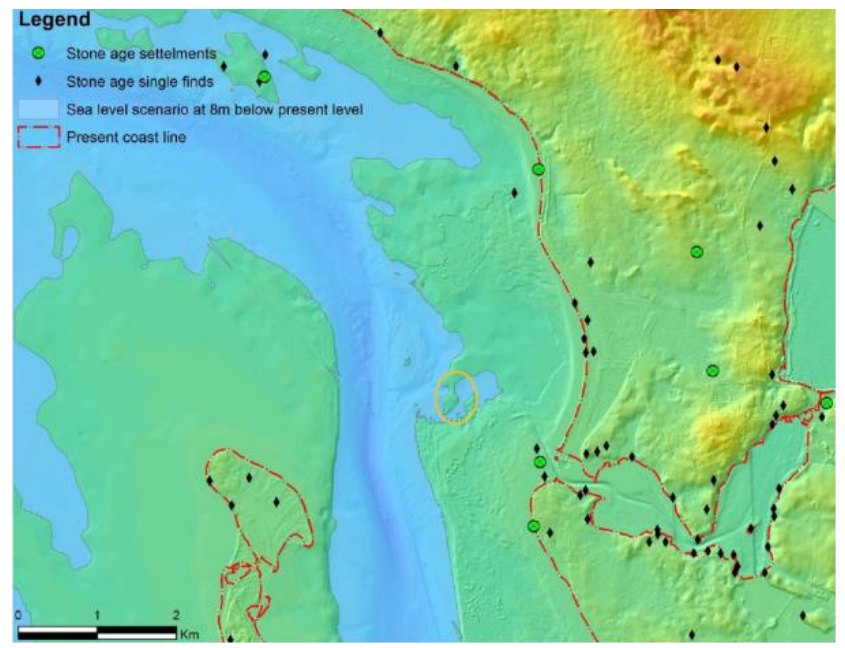

Figure 1 Geo-archaeological palaeogeographical scenario $8 m$ below present sea level ( 8000calendar years BP). Stone Age settlements and single finds from The Danish Kulturstyrelsen database for archaeological finds and sites are displayed and an orange circle indicates the position of a potential hotspot area for archaeological sites (Kongemose culture).

\subsubsection{Development of Tools for Surveying and Monitoring Coastal and Underwater Archaeological Sites}

Further to the aforementioned desktop modelling, mapping and monitoring of an archaeological site is a prerequisite for determining its location, its extent and for assessment of its physical stability. Remote sensing techniques are one of the most cost effective tools for regional scanning of the seabed surface, sediments and their morphology as well as assessing the physical stability of archaeological sites. State of the art satellite imagery techniques were used to look at coastal and sub sea topography / bathymetry of the seabed (accurate to 6 metres water depth). Furthermore more traditional methods were used such as sidescan sonar, and sub-bottom profilers, magnetometers, and single and multibeam echosounders were used to locate and map archaeological features both on and within the seabed. Although the use of these tools is not new to marine archaeology, development of existing technologies was one of the significant impacts of the SASMAP project. By contrast, 3D shallow seismic is a cutting edge method and together with other new technologies developed within the 
project, gave detailed 3D imagery of the archaeological sites and environs.

Following the down-scaling approach, and the geological models developed above seamless maps were developed that were used for assessing coastal and submerged archaeological sites. This was achieved by the following:

- multispectral satellite imagery was assimilated into a Geographical Information System (GIS), in order to map the coastline and sediment transport in 3D.

- the stability of the case study areas was investigated through observing the 3D terrain models of the sea bed surface area obtained from multibeam echosounder (MBES) surveys over the case study areas during the project time span. These data were alsoassimilated into the GIS and by comparing data sets from the satellite imagery with MBES data, hot spot areas of the sites which are being eroded, due to sediment transport or conversely covered with sediment, were identified.. A preliminary seamless map over the Danish site generated from a combination of satellite imagery and multibeam sonar survey is shown in figure 2

- a prototype 3D parametric sub bottom profiling system (SBP) was successfully developed and trialled during the project by the partner Innomar.

A combination of the above yielded "seamless" maps which enabled the transition from land to coast to sea as illustrated in Figure 2.

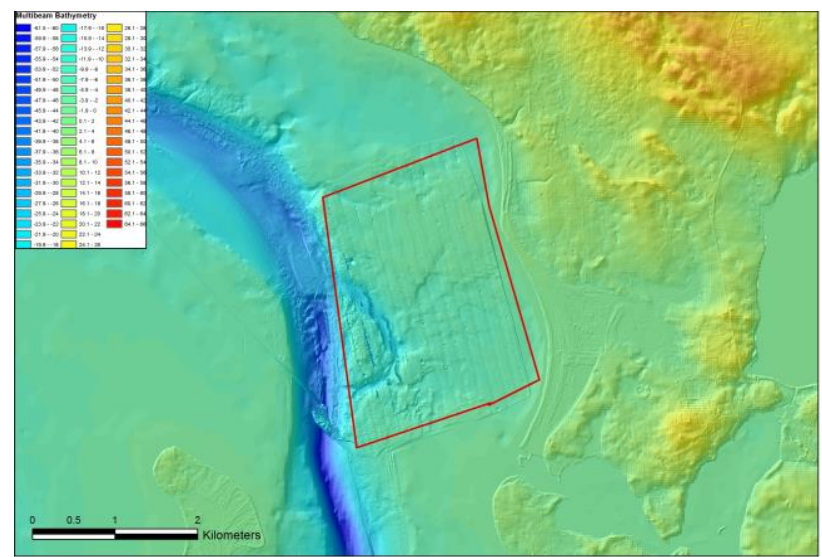

Figure 2 Combined satellite and multibeam surveys over the land coast and sea of the Danish case study site showing a truly seamless approach to mapping of coastal sites.

\subsection{Upscaling}

The down scaling approach enabled the possibility to identify "hot spots" for the location of potential archaeological sites (Figure 1) and go further to locating and surveying them (Figures 2). Having found and localised a site an upscaling approach was taken to how to deal with a site - is it stable enough to leave in situ, are materials likely to be well or poorly preserved. Depending upon these factors a decision to preserve a site in situ of excavated can be made and different methods and approaches will be necessary for this as will be discussed.

\subsubsection{Assessing the burial environment and deterioration of organic materials}

Buried waterlogged environments provide unique conditions for organic materials such as wood, bone, antler, textile, skin and plant remains to be preserved for millennia, partly due to the low oxygen levels. Conditions in open seawater can, in the absence of wood boring organisms (see http://wreckprotect.eu) also preserve these materials for many hundreds of years. However, deterioration of organic material does occur in oxygen free (anoxic) environments due to the activity of anaerobic bacteria. Research into the reburial of archaeological materials in the marine environment has shown that the rates of organic turnover (deterioration) are dependent on sediment type and their pore water composition (http://www9.vgregion.se/vastarvet/svk/reburial/index.htm).

The project has developed tools and methods to:

- A diver held vibracoring system was developed by the small company AKUT in order to take sediment core samples down to a depth of $50 \mathrm{~cm}$ without disturbing the surface layers of sediment which are very difficult to sample due to their often mobile nature (Figure 3).

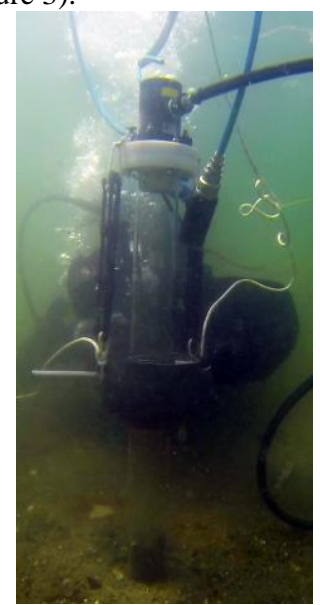

Figure 1. Core sampler. Vibracorer head uppermost with lead weight around the plastic coring tube to aid penetration of the seabed.

The device could take cylindrical cores up to $8 \mathrm{~cm}$ in diameter and was constructed in such a way that discrete layers within sediments could be easily sub sampled in order to characterize both sediment type and porewater composition in the laboratory.

- A data logging system to assess pore water composition of sediments in situ to a maximum sediment depth of $50 \mathrm{~cm}$ was developed by the small company Unisense (Figure 4). Parameters that could be measured in this way were dissolved oxygen, sulphide content, $\mathrm{pH}$, redox potential, which in combination provide information on the biogeochemical process on going in the sediment and their effect on organic material turnover.

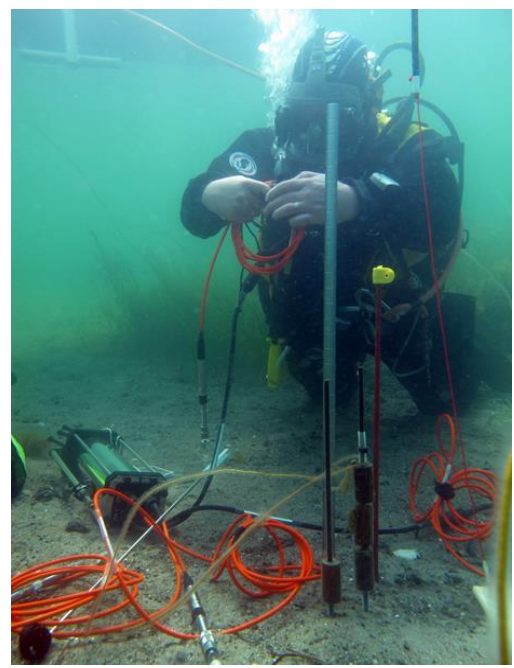

Figure 4 In situ profiling logger and spear system. 
The developed tools have been used to obtain sediment samples and monitor conditions on the test site in Denmark in order to better understand why artefacts are so well preserved, archaeologically speaking, and determine which sediment types offer the optimal conditions for preservation should sites be preserved either in situ or through re-burial. The results of this environmental monitoring are also being compared and contrasted with microscopic analysis of representative samples of archaeological wood, carried out by researchers from the Univesity of Gothenburg from the sites in order to contribute to our understanding of the effects of the environment and deterioration process of waterlogged archaeological wood.This research is ongoing and will be presented in a further publicatyion.

\subsubsection{Assessment of the state of preservation of waterlogged archaeological wood}

Waterlogged wood is one of the most frequently encountered materials on underwater archaeological sites, and knowledge of its state of preservation whilst still in situ determines whether it can be raised and subsequently conserved, or whether it is sufficiently strong to withstand being preserved in situ. Anaerobic bacteria cause deterioration of archaeological materials in marine sediments and, in the case of wood, they utilise the sugars and complex carbohydrates present in the wood cell wall as a source of nutrition. As deterioration proceeds material is removed and subsequently replaced with water - it is this water which fills the "voids" and allows the material to retain its form. Thus although freshly excavated wood may appear well preserved from an archaeological perspective, i.e. surface details and form are retained, it can be poorly preserved from a conservation perspective and if allowed to dry in an uncontrolled manner it will suffer irreversible shrinkage and collapse.

Within SASMAP a prototype hand held tool for assessing the state of preservation of waterlogged archaeological wood both in situ on the seabed and in the laboratory has been developed. By the small company AKUT and the National Museum of Denmark. The prototype is based on the non-destructive determination of the density of the wood (Figure 5).

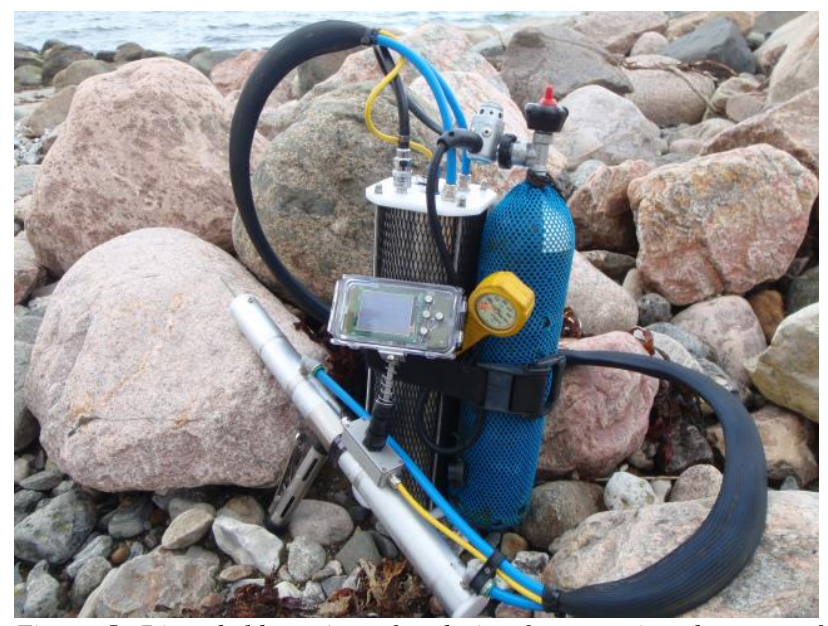

Figure 5. Diver held version of a device for assessing the state of preservation of waterlogged archaeological wood through the determination of wood density.

The net effect of bacterial deterioration is that as cell wall material is removed and replaced with water the density of the wood decreases - the more degraded the wood the lower the density. Density is a good physical parameter to provide information about the condition of wood and the implications this has for subsequent conservation or suitability for preservation in situ. Currently there is no device commercially available that can provide this information for marine archaeologists and conservators. Furthermore such a device could have broader implications for the non-destructive testing of non- archaeological timbers used in the marine environment (pilings, harbour installations) or on land (forestry, construction industry).

\subsubsection{Tools and techniques to raise waterlogged organic archaeological artefacts.}

Due to their fragility, organic archaeological materials from underwater sites can be challenging to excavate, support, raise and transport to conservation facilities. This is due to the inherent difficulties of working underwater (limited time and potentially harsh conditions) and in particular the crucial stage of lifting artefacts from the seabed to the surface where mechanical damage can easily occur. Submerged prehistoric sites in particular contain a wealth of the aforementioned organic materials and complex structures such as fish traps. To surmount this, artefacts are often raised on supporting materials or in sediment blocks (block lifting), whereby the artefact is excavated with surrounding sediment and subsequently excavated under controlled conditions on land in the laboratory. Methods of encapsulating and block lifting have been used in the past to address this, yet can be very time consuming underwater, with artefacts being left exposed to physical damage at crucial stages while consolidating materials are allowed to "set" underwater.

Within SASMAP The Italian Superior Institute for Conservation and Restoration, the Viking Ship Museum and the National Museum of Denmark have developed methods to both block lift artefacts still encapsulated within sediments and developed the use of polymer based consolidants which can both encapsulate and consolidate sediments in order to enable the safe lifting and transport of waterlogged organic archaeological objects.

\subsubsection{In situ stabilization of underwater archaeological sites}

If it is decided that a site should be preserved in situ it should not be a case of out of sight out of mind; sites can still be threatened by the natural environment. One of the biggest threats is underwater currents, which can cause sediment to be removed from sites, leading to their exposure. Upon exposure, sites are susceptible to mechanical abrasion and erosion, which can lead to their total loss. Furthermore, wooden artefacts can, under the right environmental circumstances, be attacked by wood boring organisms such as shipworm, which can also lead total loss of archaeological materials within relatively short periods of time - years or decades rather than centuries or millennia. The EU supported project Wreck Protect (http://www.wreckprotect.eu) assessed ways to protect historical wooden shipwrecks in situ from the threat of wood boring organisms. All potential methods identified relied upon limiting the access of oxygen to the wood and this can most simply be achieved by covering with sediment. However, simply covering with sediment may not be sufficient as it may itself be washed away. Innovative methods identified actually took advantage of currents and sediment transport within the water column to either entrap sediment and create a burial mound or disperse currents so that seabed erosion was reduced. The small company Seabed Scour Control Systems is a world leader in scour control systems to prevent seabed scouring and erosion for the offshore industry (gas and oil pipelines, offshore wind turbine footings). To achieve this they use mats of artificial 
seagrass, which float upright in the water column and entrap passing sediment particles, effectively creating an artificial seabed. The mats have been developed further to test their applicability to protecting shallow water submerged archaeological sites, which are under threat from near shore and coastal erosion and an example of a mat is shown in Figure 6.

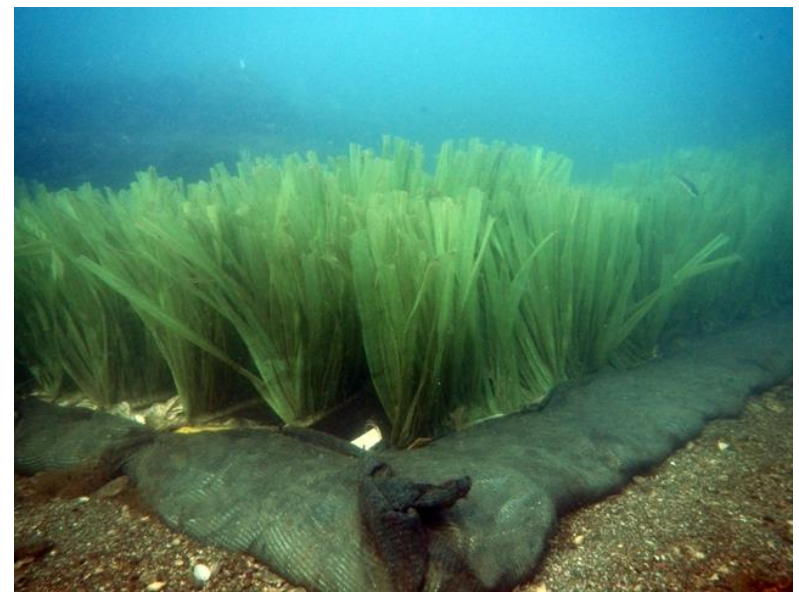

Figure 6. An artificial seagrass mat on the seabed. The plastic fronds work in two ways; catch sediment suspended in the water column and creat a burial mount or if there is no sediment transport they can slow down water currents.

\section{IMPACTS OF SASMAP}

SASMAP with its holistic and process based approach to underwater cultural heritage has provided an improved understanding of the environment of underwater archaeological sites. The results of the various tools and techniques have been formulated into two guidelines that will contribute to best practice for management decisions. Although in situ preservation should be seen as a first option for the preservation of underwater cultural heritage this is not always viable due to either the nature of the site environment or the fact that, due to subsea development, sites have to be excavated. SASMAP addresses both these scenarios. The innovative tools and new technologies that will be developed to improve both location and mapping of sites; the excavation and raising of fragile organic materials if it is not viable to preserve them in situ. If in situ preservation is an option, SASMAP has developed new technologies to stabilise sites and monitor their effectiveness and also the effects these stabilisation materials have on the environment.

Future funding from the European Union for research projects will see an increasing demand for the inclusion of small companies in line with current European policy. The SASMAP consortium includes four SME partners. The SMEs are already leaders in their respective fields and the project is mutually beneficial as it has provided the SMEs the opportunity to fulfil many of their own business development plans and develop new tools and technologies. The impact of these new technologies has wider implications than just the SASMAP project and will enable the SMEs to increase their business profiles after the completion of the project.

SASMAP has adopted a European rather than a national approach because the implications of the Treaty of Valletta affect all European nations with territorial waters and thus responsibility for dealing with underwater archaeology

The development of the SASMAP technologies required strong collaboration between complementary research disciplines that are only found at a European level. Moreover, the involvement of four SMEs in the project was only possible due to the European approach taken. The active involvement of these SMEs has ensured awareness and effective dissemination of the technologies to heritage agencies, cultural resource managers and end users in the offshore sub sea industry. These activities are of vital importance for successful exploitation and marketing of the technologies beyond SASMAP. By taking a European approach, SASMAP has improved the assessment of underwater archaeology in connection with sub sea development by providing heritage agencies with new tools and best practices

The project has produced two main products; Prototype technologies, and other tools and methods which will contribute to best practice when investigating underwater archaeological sites. The prototype tools developed by the SMEs will be disseminated through both the project's own home page and the home pages of the SMEs involved along with media (TV, radio, press) coverage. Intellectual property of the prototypes will be the rights of the SMEs but directions for their practical use will form an integral part of the guidelines produced in the project Furthermore, the tools and techniques developed to locate, assess and manage underwater cultural heritage will be synthesised into two guidelines. Further to the prototypes and the guidelines, the project results are being disseminated through publication in peer reviewed scientific journals, popular press, presentations at national and international conferences for marine archaeology, conservation and subsea development. It is also hoped that the project can contribute to European policy for the improved management of Europe's underwater cultural heritage. For further information on the results of the project the reader is referred to the project home page: www.sasmap.eu

\section{$4 . \quad$ SELECTED REFERENCES}

Bjõrdal, C.G. and Gregory, D. (2012) Wreck Protect: Decay and Protection of Archaeological Wooden Shipwrecks. Archaeopress, Oxford.

Al-Hamdani, Z.K., Reker, J., Leth, J.O., Reijonen, A., Kotilainen, A.T, Dinesen G.E. 2006 Development of marine landscape maps for the Baltic Sea and the Kattegat using geophysical and hydrographic parameters." Review of Survey activities 2006. GEUS bulletin 13, 61-64.Archaeological Materials.

Hermansen, B., Jensen, J.B. 2000. Digital Sea Bottom Sediment Map around Denmark. GEUS report2000/68. in a Variety of Environments of Differing Saturation Level.

Petriaggi, R., Mancinelli, R., (2004), An experimental conservation treatment on the mosaic floor and perimeter walls of room n.1 of the so-called "Villa con ingresso a Protiro" in the Underwater Archaeological Park of Baia, Archaeologia Maritima Mediterranea , 1, pp. 109-126;

\section{ACKNOWLEDGEMENTS}

The project SASMAP has been made possible with funding from the European Commission, grant number 308340, under the Environment working theme, ENV. 2012.6.2-6. Development of advanced technologies and tools for mapping, diagnosing, excavating and securing underwater and coastal archaeological sites. The author would also like to thank the EC project officers for the project, for their continual help, support and encouragement. 